\title{
Targeted opportunities to address the climate-trade dilemma in China
}

\author{
Zhu Liu ${ }^{1,2,3}$, Steven J. Davis ${ }^{4,5 \star}$, Kuishuang Feng ${ }^{6,7 \star}$, Klaus Hubacek ${ }^{6}$, Sai Liang ${ }^{8}$, Laura Diaz Anadon ${ }^{1,9}$, \\ Bin Chen ${ }^{10}$, Jingru Liu" ${ }^{11}$ Jinyue Yan ${ }^{12,13}$ and Dabo Guan ${ }^{14,15 \star}$
}

\begin{abstract}
International trade has become the fastest growing driver of global carbon emissions, with large quantities of emissions embodied in exports from emerging economies. International trade with emerging economies poses a dilemma for climate and trade policy: to the extent emerging markets have comparative advantages in manufacturing, such trade is economically efficient and desirable. However, if carbon-intensive manufacturing in emerging countries such as China entails drastically more $\mathrm{CO}_{2}$ emissions than making the same product elsewhere, then trade increases global $\mathrm{CO}_{2}$ emissions. Here we show that the emissions embodied in Chinese exports, which are larger than the annual emissions of Japan or Germany, are primarily the result of China's coal-based energy mix and the very high emissions intensity (emission per unit of economic value) in a few provinces and industry sectors. Exports from these provinces and sectors therefore represent targeted opportunities to address the climate-trade dilemma by either improving production technologies and decarbonizing the underlying energy systems or else reducing trade volumes.
\end{abstract}

$\mathrm{D}$ espite international efforts to reduce $\mathrm{CO}_{2}$ emissions ${ }^{1,2}$, global emissions have increased by an average of $3.1 \%$ per year since 2000 (refs 3,4). Economic growth has been identified as the main driver of the sharp increase of $\mathrm{CO}_{2}$ emissions in the 2000s, and in particular the rapid industrialization of China ${ }^{5}$, which has become the world's largest carbon emitter since 2006 (ref. 6). However, China is also the world's largest net exporter of $\mathrm{CO}_{2}$ emissions embodied in goods and services. In 2007, emissions in China were $7.3 \mathrm{GtCO}_{2}$, (production-based emissions), of which $1.7 \mathrm{Gt}(23 \%)$ were related to goods exported and ultimately consumed in other countries, ${ }^{7,8}$. In contrast, only $0.2 \mathrm{GtCO}_{2}$ emissions were embodied in products imported to China from other countries. As of 2008, Chinese trade accounted for a third of all emissions embodied in global trade, and these traded emissions have been growing faster than global emissions ${ }^{9}$. The magnitude and growth of emissions embodied in Chinese trade pose a dilemma for trade and climate policy: to the extent China and other emerging markets have comparative advantages in manufacturing, international trade is economically efficient and desirable ${ }^{10}$. However, if carbonintensive manufacturing in China entails drastically more carbon emissions than making the same product elsewhere, then trade increases global carbon emissions. Yet, although previous studies have quantified emissions embodied in China's trade ${ }^{7,11-13}$, none have quantified the underlying factors driving these emissions, leaving open the question of how to mitigate such embodied emissions.
Here, we decompose the key factors contributing to the prodigious imbalance of emissions embodied in China's international trade (see Methods for details): the large trade surplus between China and its trading partners; the structure of the Chinese economy (that is, specialization in energy-intensive production); the energy mix of China's production (that is, energy mainly supplied by fossil fuels); and the emissions intensity of Chinese production (that is, the emissions produced per unit of economic output ${ }^{10,11}$. China is a country with substantial regional differences in technology, energy mix and economic development, as well as large volumes of interprovincial trade ${ }^{8,14-17}$, our analysis assessed the magnitude and intensity of emissions from 46 industry sectors (Supplementary Table 1) traded among 30 Chinese provinces/cities and 128 other countries/regions.

Details of the analytical approach are presented in Methods. We track emissions embodied in trade among 158 regions using a global multiregional input-output (MRIO) model of emissions and trade as of the year 2007. The trade and emissions data supporting the model are a combination of the Global Trade Analysis Project (GTAPv8) and province-level input-output tables of China that we have previously constructed ${ }^{8,15,18}$. We analyse the driving factors of emissions embodied in international trade using an improved index decomposition approach (IDA; refs 15,19). The results presented below and in the figures reflect only international trade. Our model links physical production of emissions with the consumption of final

1John F. Kennedy School of Government, Harvard University, Cambridge, Massachusetts 02138, USA. ${ }^{2}$ Resnick Sustainability Institute, California Institute of Technology, Pasadena, California 91125, USA. ${ }^{3}$ Cambridge Centre for Climate Change Mitigation Research, Department of Land Economy, University of Cambridge, 19 Silver Street, Cambridge CB3 9EP, UK. ${ }^{4}$ University of California, Irvine, Department of Earth System Science, Irvine, California 92697, USA. ${ }^{5}$ Institute of Applied Ecology, Chinese Academy of Sciences, Shenyang 110016, China. ${ }^{6}$ Department of Geographical Sciences, University of Maryland, College Park, Maryland 20742, USA. ${ }^{7}$ Center for Environment Policy Research, Institute of Policy and Management, Chinese Academy of Sciences, Beijing 100190, China. ${ }^{8}$ School of Natural Resources and Environment, University of Michigan, Ann Arbor, Michigan 48109-1041, USA. ${ }^{9}$ Department of Science, Technology, Engineering and Public Policy, University College, London W1T 6EY, UK. ${ }^{10}$ State Key Joint Laboratory of Environmental Simulation and Pollution Control, School of Environment, Beijing Normal University, Beijing 100875, China. ${ }^{11}$ State Key Laboratory of Urban and Regional Ecology, Research Center for Eco-Environmental Sciences, Chinese Academy of Sciences, 100085 Beijing, China. ${ }^{2}$ KTH-Royal Institute of Technology, SE-100 44 Stockholm, Sweden. ${ }^{13}$ Malardalen University, SE-721 23, Sweden. ${ }^{14}$ Ministry of Education Key Laboratory for Earth System Modeling, Center for Earth System Science, Tsinghua University, Beijing 100084, China. ${ }^{15}$ Tydnall Centre for Climate Change Research, School of International Development, University of East Anglia, Norwich NR4 7TJ, UK. *e-mail: sjdavis@uci.edu; kfeng@umd.edu; dabo.guan@uea.ac.uk 
a
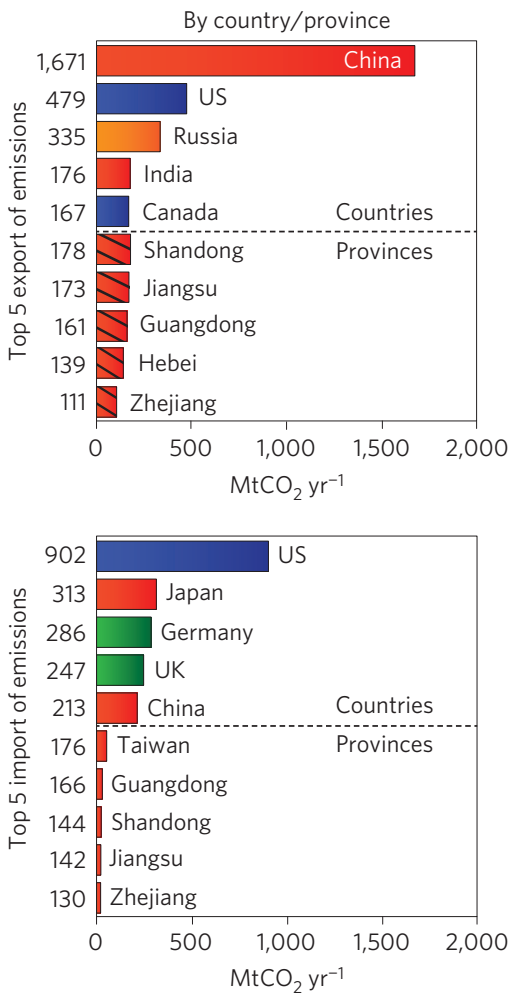

g

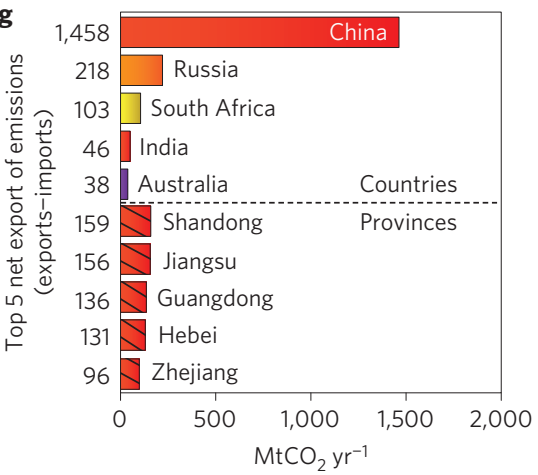

South and East Asia b

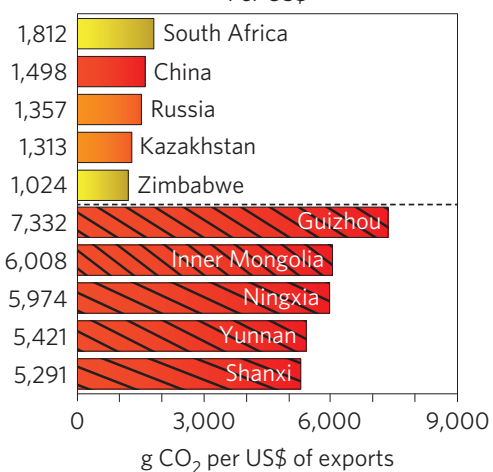

e

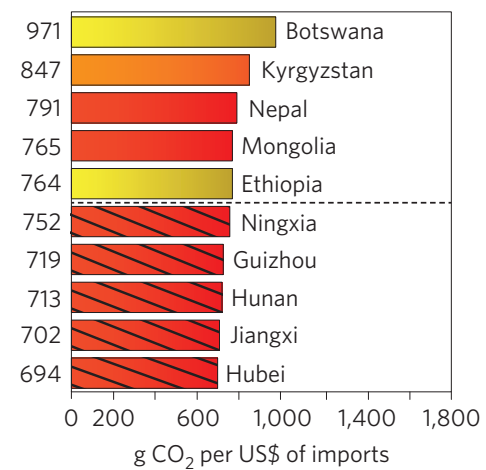

h

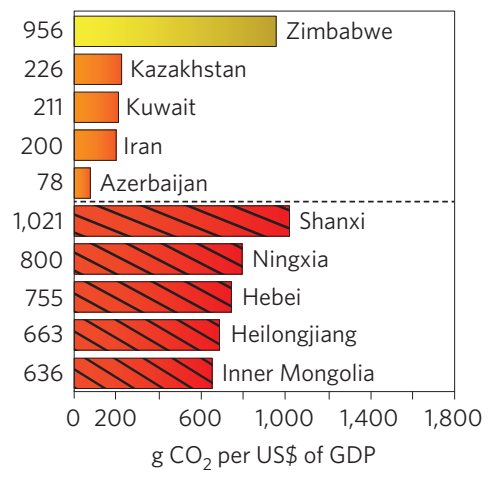

c

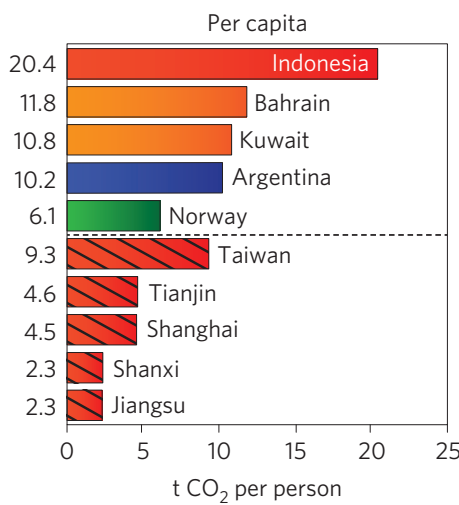

f

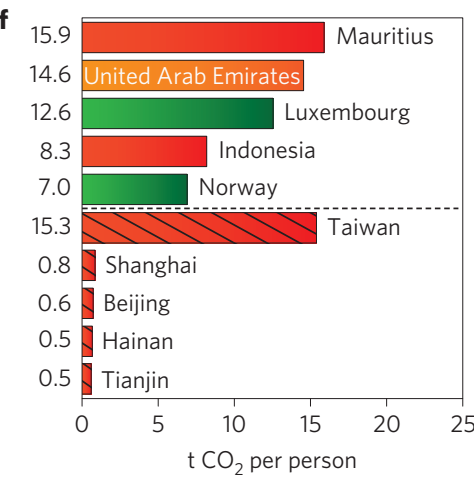

i

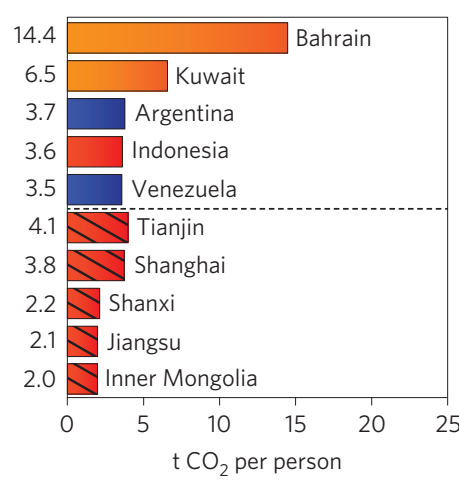

Mideast and Central Asia

Americas

Europe

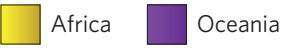

Figure 1 | Emissions embodied in trade. Top ten regions (including top five countries and top five Chinese cities/provinces) by emissions embodied in exports (a-c), imports $(\mathbf{d}-\mathbf{f})$ and net trade $(\mathbf{g}-\mathbf{i})$, shown in absolute numbers $(\mathbf{a}, \mathbf{d}, \mathbf{g})$, per dollar of output $(\mathbf{b}, \mathbf{e}, \mathbf{h})$ and per capita $(\mathbf{c}, \mathbf{f}, \mathbf{i})$. Data is for 2007.

goods without regard for the location of intermediate consumption. For example, emissions related to components manufactured in Inner Mongolia that become part of a product assembled in Beijing and are exported to another country are assigned to Inner Mongolia. If the same final product was exported to another Chinese province, the embodied emissions are consumed domestically and are therefore excluded from our analyses.

\section{Emissions embodied in Chinese exports}

Figure 1 shows the top five countries and the top five Chinese provinces whose exports, imports and net trade embody the greatest $\mathrm{CO}_{2}$ emissions, including the greatest emissions per unit of economic output and per capita. China is the largest net exporter of embodied emissions, by a large margin (Fig. 1g) with eight times more emissions embodied in its exports than its imports (Fig. 1a,d). In contrast, this ratio of emissions embodied in exports to imports is much less in other major exporting nations (for example, 0.5 in the US, 0.5 in Japan, 1.3 in India, 1.2 in Canada, 0.5 in Germany and 1.5 in Australia).
All of the 30 Chinese provinces assessed are net exporters of embodied emissions, meaning that in all cases the emissions embodied in exports exceed the emissions embodied in imports Fig. 1 also highlights the significance of particular Chinese provinces; seven of the top ten net exporting regions are Chinese provinces-larger than many large nations (Fig. 1g). Furthermore, the ratio of emissions embodied in exports to imports in these Chinese provinces is immense: 11 of China's 30 provinces export more than ten times as much emissions as they import, including Xinjiang, Shanxi and Hebei, whose export-import ratios are the largest of any region in our model: 25, 19 and 16, respectively. Five provinces account for $46 \%$ of the $1,671 \mathrm{MtCO}_{2}$ embodied in China's exports in 2007: Shandong (178 $\left.\mathrm{MtCO}_{2}\right)$, Jiangsu $\left(173 \mathrm{MtCO}_{2}\right)$, Guangdong (161 $\left.\mathrm{MtCO}_{2}\right)$, Hebei $\left(139 \mathrm{MtCO}_{2}\right)$ and Zhejiang (111 $\mathrm{MtCO}_{2}$; Fig. 1a).

China's provinces are also the most carbon-intensive exporters in the world. The average emissions embodied per dollar of Chinese exports is $1,357 \mathrm{~g} \mathrm{CO}_{2} / \mathrm{US} \$$, which is about six times the average emissions embodied per dollar of China's international imports 

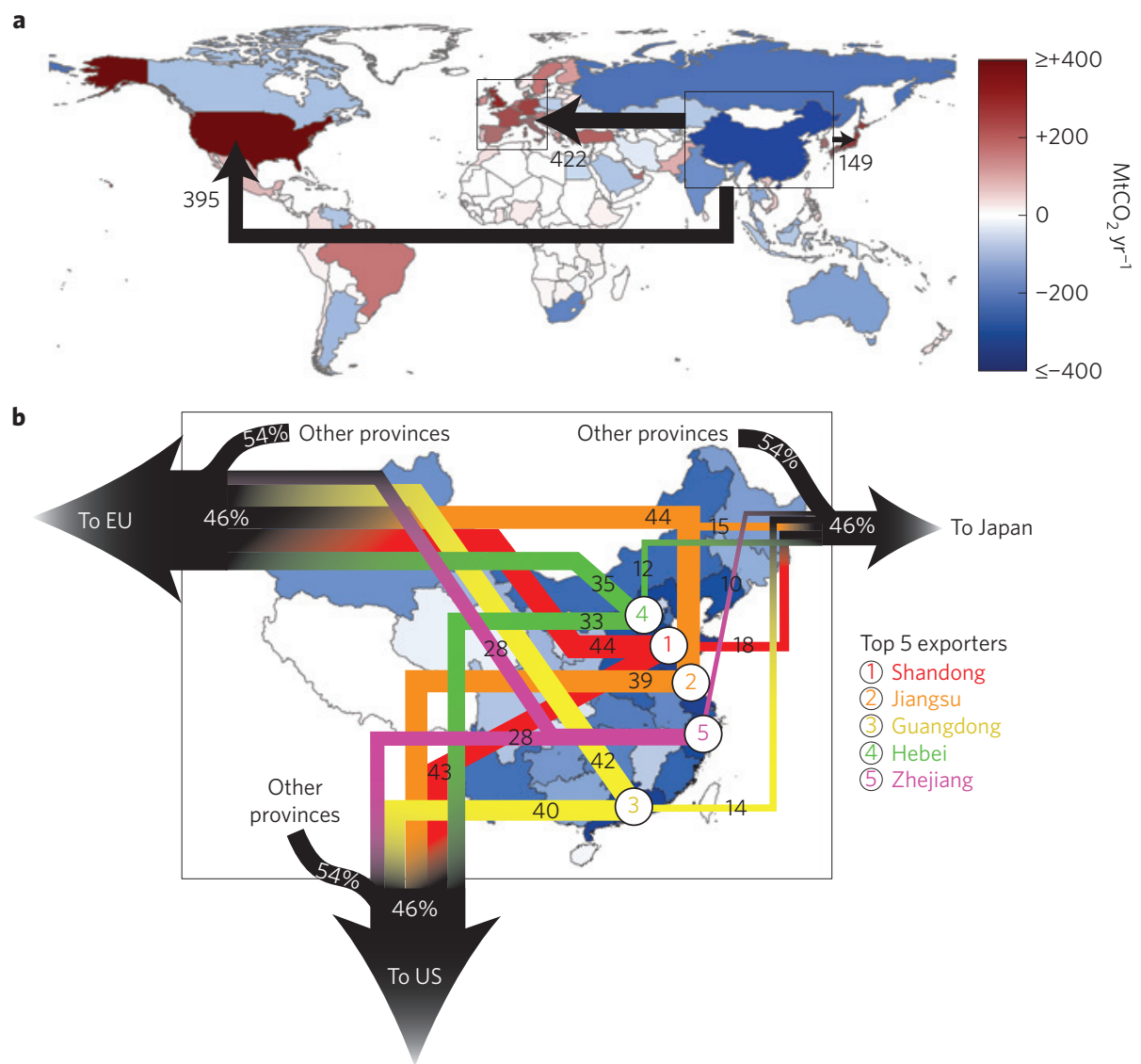

Figure 2 | China's emission exports and the top exporting provinces. a, The emissions embodied in goods exported from China to the US, EU and Japan are shown, representing 58\% of all emissions embodied in trade in 2007 (the largest flows are labelled in $\mathrm{MtCO}_{2} \mathrm{yr}^{-1}$ ). b, The five Chinese provinces accounting for $46 \%$ of these exports. Percentages of total exported emissions from the top 5 exporters and all other provinces are labelled in white, with the $\mathrm{MtCO}_{2} \mathrm{yr}^{-1}$ of each contribution labelled in black.

( $\left.230 \mathrm{~g} \mathrm{CO}_{2} / \mathrm{US} \$\right)$. This is reflected in the very high emissions embodied per dollar of exports from individual provinces, which comprise all of the top ten regions in this category (Fig. 1b). The provinces with the greatest emissions intensity of exports also tend to be less economically developed; provinces where GDP is less than US $\$ 4,000$ per capita show the largest difference in the emission intensity of exports and imports (Supplementary Fig. 1). About 80\% of China's export-related emissions are produced by these poorer regions, where the emissions intensity of exports is more than five times the emissions intensity of imports. For example, in Guizhou, where per capita GDP was US\$900 in 2007, the emissions intensity of international exports was almost 31 times the emissions intensity of imports (Supplementary Fig. 1). Similarly high ratios exist in the also poor provinces of Inner Mongolia, Yunnan and Gansu. In the more affluent coastal provinces, ratios of emissions intensity of exports to imports are much smaller: ratios in Beijing, Zhejiang and Shanghai are 2.8, 3.0 and 4.1, respectively. But even these ratios are still much higher than those of other large trading nations such as US (0.8), Germany (0.4), Japan (0.2), Canada (1.1), the UK (0.3) and India (1.7).

Although it is the most populous country in the world, since 2013 China's per capita emissions are approaching the average level in Europe when one ignores the fact that a large fraction of emissions are destined to exports ${ }^{20,21}$. However, the per capita net export of embodied emissions from some Chinese provinces is also much larger than most developed countries, three Chinese provinces among the top ten in the category of global 158 regions (Fig. 1i), and 15 of China's 30 provinces could listed as the world top 30 regions with the highest net trade emissions per capita.
Figure 2 shows the destination of exports from the five provinces whose exports embody the greatest emissions (see also Fig. 1g). Just five provinces, Jiangsu, Shandong, Guangdong, Hebei and Zhejiang represent $10.7 \%, 10.4 \%, 9.7 \%, 8.3 \%$ and $6.7 \%$ of all emissions embodied in China's exports, respectively (Fig. 2). As previous studies have shown ${ }^{22,23}$, developed countries are the primary importers of Chinese embodied emissions, foremost among them being the US (395 $\mathrm{MtCO}_{2}, 24 \%$ of China's exported emissions and $44 \%$ of the US's imported emissions, respectively), the EU (422 $\mathrm{MtCO}_{2}, 25 \%$ and 42\%, respectively) and Japan (149 $\mathrm{MtCO}_{2}$, $9 \%$ and $48 \%)$.

\section{Driving factors of China's carbon-intensive trade}

Several factors can contribute to the observed differences in the magnitude and intensity of emissions embodied in exports and imports. First, in recent years China has become a 'factory for the world', with high concentrations of global heavy industry and manufacturing. For example, China produces $60 \%, 51 \%$ and $65 \%$ (by mass) of the world's cement, steel and coke, respectively ${ }^{24}$. Such large imbalances in the volume of traded products may correspond to similarly large imbalances in the emissions embodied in traded products. Figure 3 compares emissions embodied in imports and exports by industry sector in China (Fig. 3a) and Europe (Fig. 3b). For example, $34 \%\left(26 \mathrm{MtCO}_{2}\right)$ of emissions produced by the European metal production industry are embodied in products exported from Europe in 2007, but emissions embodied in all metal products consumed in Europe were $140 \mathrm{MtCO}_{2}, 64 \%$ of which $\left(90 \mathrm{MtCO}_{2}\right)$ were imported from outside Europe (Fig. 3a; red circle labelled 'Metal'). In comparison, the share of emissions produced 
a

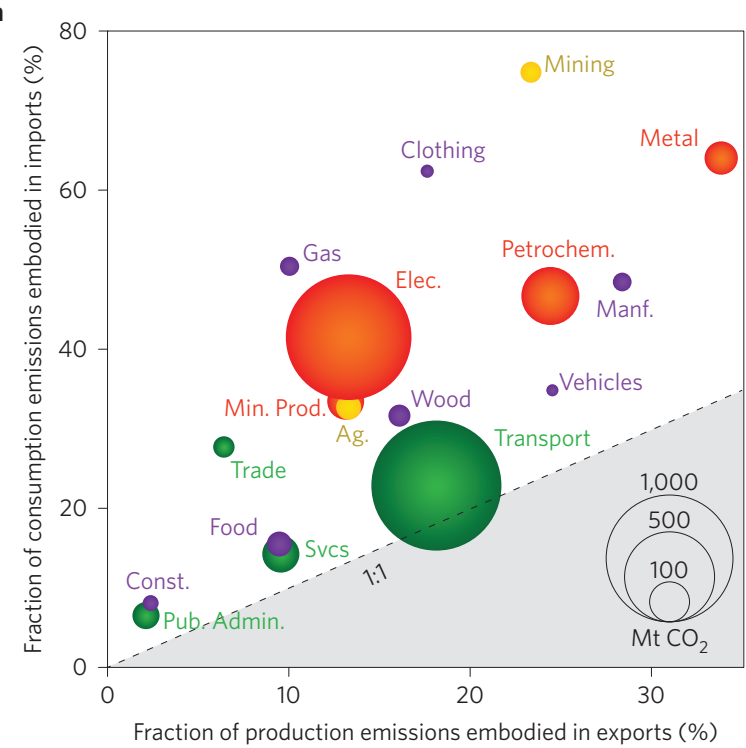

b

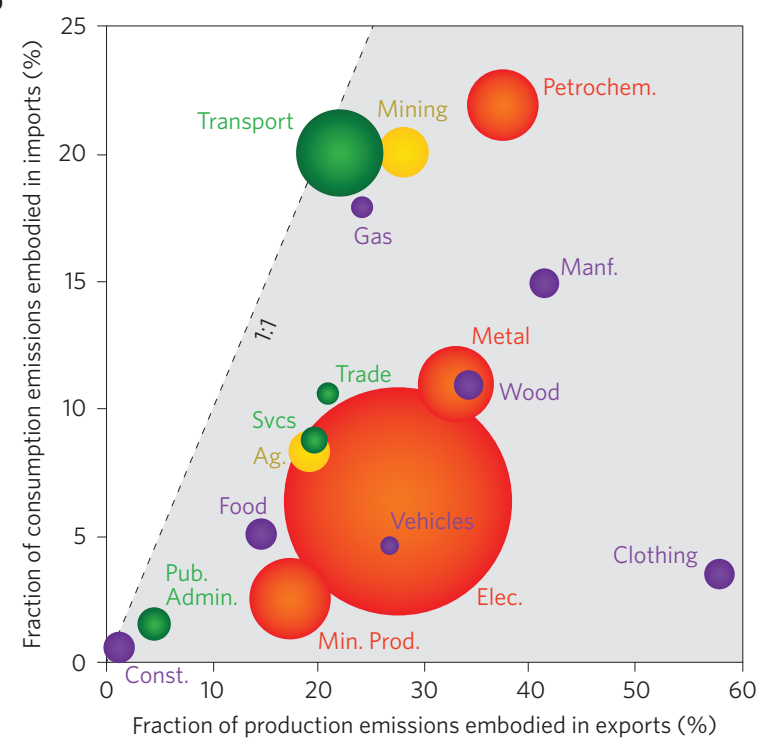

Figure 3 | Differences in share of embodied emissions traded by industry categories. Circles indicate the share of consumed emissions that are imported and the share of produced emissions that are exported for a range of industry categories in Europe (a) and China (b). The size of each circle denotes the sector's total production emissions, providing an indicator of the relative importance of different sectors. The colours of the circles indicate whether the industries are primary (yellow), secondary and energy intensive (red), secondary and non-energy intensive (purple) or tertiary (green). For a list of sector abbrevations see the Supplementary Information. It should be noted that, although the marker area scale is common across both charts (to aid comparison), the $x$ - and $y$-axis scales differ. A line representing equal import and export share is shown in each chart. Data is for 2007.

by China's metal production sector that is exported is similar to Europe's (33\%; Fig. 3b), but the share of emissions related to Chinese consumption of metals that is imported is much lower (11\%).

Overall, Fig. 3 highlights that, across many industry sectors, the share of European consumption (import from other countries) is consistently greater that the share of produced emissions that are exported, and the opposite is true for China. These trade imbalances are evident for both industries (yellow circles) and secondary industries (red and purple circles).

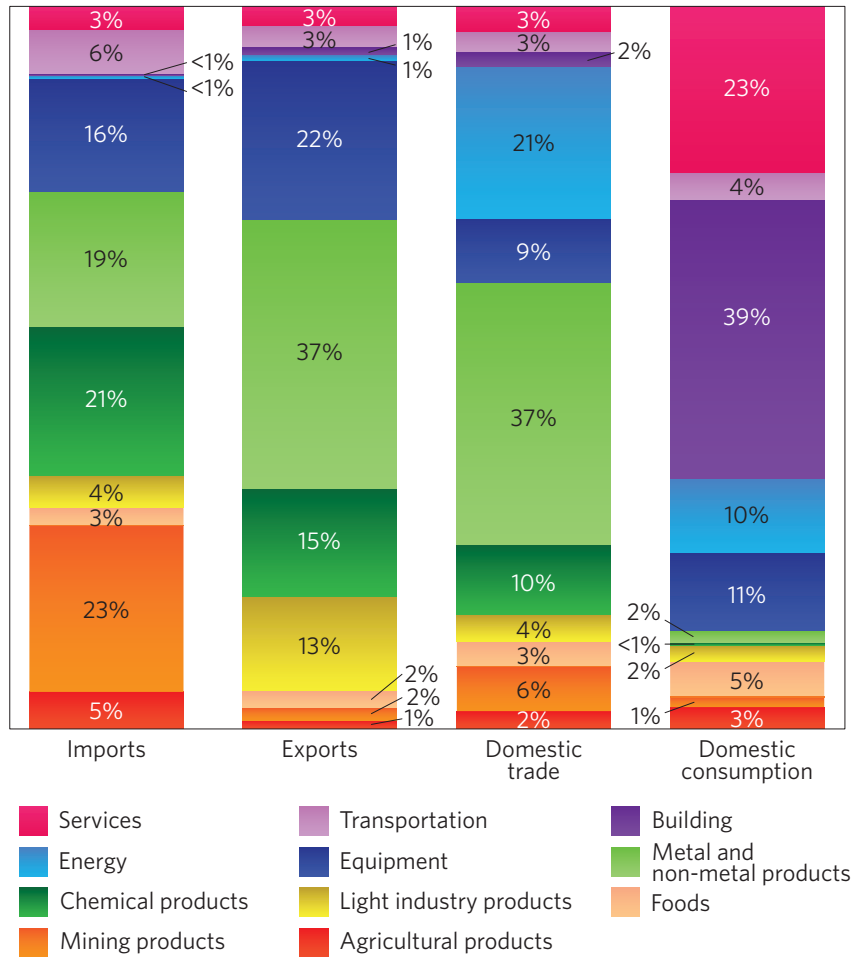

Figure 4 | Sectoral share of China's embodied emissions. Data is for 2007.

A second factor influencing emissions embodied in trade is the trade structure. Figure 4 shows the industry categories that make up Chinese imports, exports and domestic consumption. Emissions embodied in heavy, energy-intensive products such as metal and non-metal products and equipment make up much larger shares of China's exports (37\% and $22 \%$, respectively) than its imports (19\% and 16\%, respectively; light green and dark blue bars in Fig. 4). Meanwhile, mining products is the category with the greatest proportion of emissions embodied in Chinese imports (23\%). The dominance of these industries in Chinese trade implies that China is not just the world's workshop, but is engaged in the most emissionintensive stages of manufacturing: the smelting and processing of raw materials. This pattern is visible at the province level, as well; in Shandong, where emissions embodied in trade are largest, 8 $\mathrm{MtCO}_{2}$ are embodied in imports of mining products from other countries (42\% of all emissions embodied in imports) and $60 \mathrm{MtCO}_{2}$ are embodied in exported metal and non-metal products $(34 \%$ of emissions embodied in the province's exports).

The third major factor is emissions intensity, or $\mathrm{CO}_{2}$ emissions per dollar of output in each particular industry. Such emissions intensity reflects both energy intensity (energy consumed per dollar of output) and carbon intensity of energy $\left(\mathrm{CO}_{2}\right.$ per unit of energy consumed). The combination of a carbon-intensive power industry, relying primarily on coal, and of a relatively low-valueadded industry thus translate into a high emissions intensity of Chinese production (Figs $1 \mathrm{~b}, \mathrm{~h}$ and 2 ). In 2007, 75\% of China's primary energy was supplied by coal, the highest level among major energy-consuming nations. As a result, the carbon intensity of energy consumption in general (for internal consumption and exports combined) in China is extremely high: Chinese exports entail $61 \mathrm{t} \mathrm{CO}_{2} \mathrm{PJ}^{-1}$ on average, which is almost triple the carbon intensity of imports to China, $24 \mathrm{t} \mathrm{CO}_{2} \mathrm{PJ}^{-1}$. The energy intensity of China's exports is similarly high; in 2007, China consumed $22 \mathrm{MJ}$ per dollar of output, on average, or more than twice the energy intensity of products imported to China (9 MJ per US\$). This high energy intensity is underpinned by the low-value-added goods and less advanced technology of China's production, as 


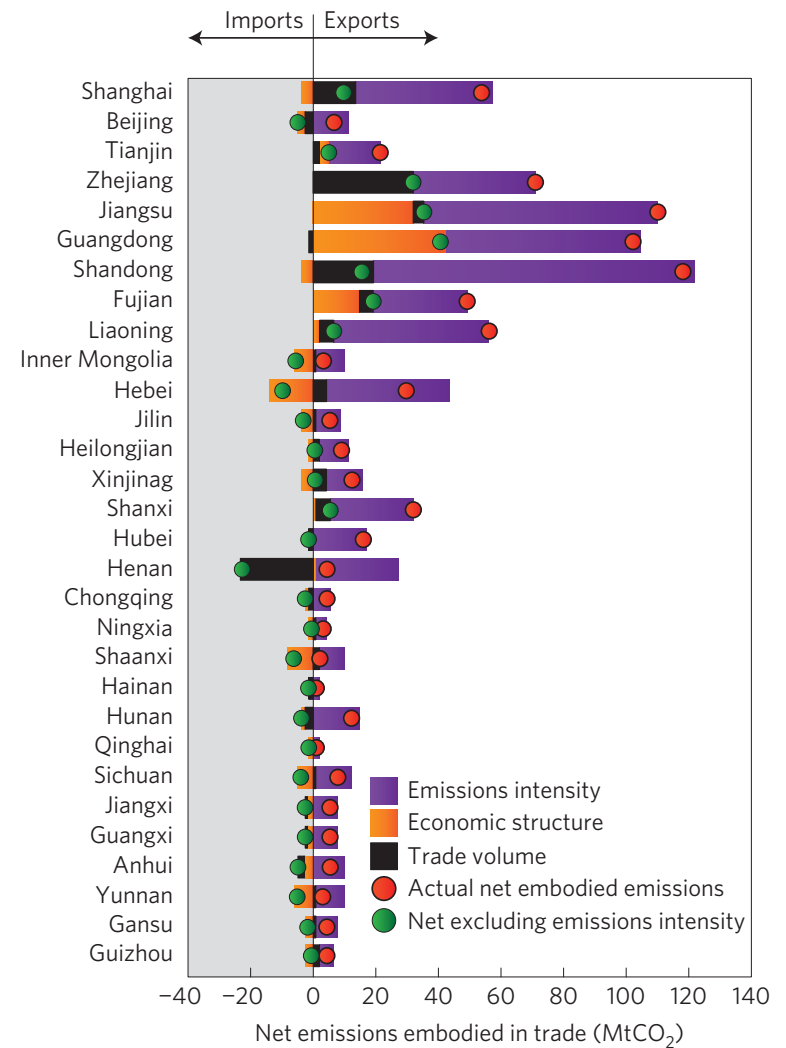

Figure 5 | Factors contributing to emissions embodied in provincial trade. Decomposition of factors underlying emissions embodied in trade for each of 30 Chinese cities/provinces. Net emissions embodied in trade (red circles) are equal to emissions embodied in exports minus emissions embodied in imports. Black bars show the effect of unbalanced trade volume; orange bars show the effect of differences in the industry sectors involved in trade (that is, trade structure, for example, the proportion of heavy industries); and purple bars show the effect of differences in the emissions intensity of imported and exported goods. Green circles show what net emissions embodied in trade would be if there was no difference in the emissions intensity of imported and exported goods - that is, if trade volume and economic structure were the only factors affecting embodied emissions. In reality, all 30 regions are net exporters of emissions, but only 11 of the 30 would remain net exporters of emissions if differences in emissions intensity were eliminated.

previously suggested by other studies ${ }^{22,25}$ covering the 2002-2010 time period.

Supplementary Fig. 2 further indicates that the industry sectors with the greatest emissions intensity in each of the six Chinese top carbon export provinces (see also Fig. 1b). Although there is some variation among the emissions intensity of sectors in these six provinces, the manufacture of heavy industrial materials for export (for example, mining products, chemical products, metal/non-metal products, and energy) is many times higher than the emissions intensity of similar products that are imported and consumed in China (Supplementary Figs 1, 2 and 3).

Figure 5 shows the contribution of the different factors to the net emissions embodied in trade of each Chinese province. Four factors are decomposed: differences in the total economic value of exports and imports (trade volume, black bars), where greater trade volumes correspond to greater embodied emissions; differences in sectors responsible for exports and imports (economic structure, orange bars), where greater shares of energy- and emission-intensive heavy industry and manufacturing, for example, correspond to greater embodied emissions; differences in the carbon-intensity of energy used to produce exports and imports, where a greater
Table 1 | Life cycle carbon emission intensity for 15 products from China and EU.

\begin{tabular}{lll} 
& China* & EU* \\
\hline Flat glass production & 2.55 & 1.05 \\
Crushed limestone & 4.53 & 1.81 \\
Propylene & 21.2 & 1.15 \\
ABS & 11.6 & 3.63 \\
Copper concentrate & 0.436 & 0.357 \\
Steel by electricity stove & 5.23 & 3.62 \\
Steel production & 5.68 & 1.97 \\
Cast iron production & 5.45 & 1.31 \\
Aluminium ingot production & 68.4 & 10.4 \\
Cast iron production & 5.45 & 1.31 \\
Pig iron production & 3.23 & 1.34 \\
Iron sinter production & 1.89 & 0.331 \\
Magnesium alloy production & 34.3 & 11.5 \\
Anode slime copper production & 4.82 & 3.4 \\
Water production & 0.00196 & 0.0003 \\
\hline
\end{tabular}

*Intensities listed are national averages $\left(\mathrm{kgCO}_{2} \mathrm{~kg}^{-1}\right)$.

share of low-carbon energy sources such as renewables and nuclear correspond to less embodied emissions; and differences in the sectoral energy intensity of exports and imports, where greater shares of low-energy, high-value-added products correspond to less embodied emissions (the latter two factors are combined and shown as emissions intensity, purple bars).

On average, the high energy intensity of sectors and the coaldominated energy mix accounted for $43.3 \%$ and $43.0 \%$ of the net emissions embodied in exports, respectively (Fig. 5). In comparison, the structural preference for manufacturing and heavy industry accounted for only $8 \%$ of the net emissions embodied in exports, and less than $6 \%$ of the net exports are related to the larger volume of exports than imports. Emissions intensity (contributed by both energy intensity and carbon intensity of sectoral energy use) is the most important factor underlying the large net exports of embodied emissions, accounting for $86 \%$ of the emissions embodied in exports, or 1,438 $\mathrm{MtCO}_{2}$ of emissions. All 30 regions are net exporters of emissions, but only 11 of the 30 would remain net exporters of emissions if differences in emissions intensity were eliminated. The emission-intensive manufacturing reflects China's current development status with features discussed above.

\section{Discussion}

We show that the very large quantities of net emissions embodied exported from China are probably due primarily to Chinese reliance on coal energy and the very high energy intensity of the exporting industries, which are in turn geographically concentrated in a small number of less-developed provinces.

Our analysis is based on aggregated sectors (for example, electronic equipment and machinery) rather than the specific products (for example, iPhones), such that we may underestimate the effect of economic structure on net trade of emissions if differences in production are too specialized to be reflected by the 46 sectors in our model (Supplementary Table 1). The comprehensive data necessary to support product-level analysis are not yet available. However, we also used up-to-date and independent life cycle analysis data sets (PRé SimaPro LCA 7.3 data set ${ }^{26}$ for Europe and RCEES 2012 database $^{27}$ for China) to investigate the carbon emission per unit product of the production process for a sample of 15 industrial products made in Europe and China (Table 1). Doing so revealed that the emissions per unit mass of each product $\left(\mathrm{kgCO}_{2} \mathrm{~kg}^{-1}\right)$ for Chinese products was on average 4.4 times higher than the same products made in Europe, ranging 
from 1.4 times as high for copper production to 18.4 times as high for propylene production (Table 1).

Product-level data are therefore entirely consistent with our more aggregated sector-level analysis showing that production in China is several times as carbon intensive as the same production in other countries, supporting our conclusion that the emissions intensity of Chinese production is the main factor driving the country's large net exports of embodied emissions. This suggests that, although international trade with China may be economically optimalgiven, for instance, comparative advantages in labour costs-such trade is on average causing increase global $\mathrm{CO}_{2}$ emissions relative to production taking place in the countries which now import from China.

However, because Chinese emissions intensity is highest in a small number of provinces and sectors, targeted changes in primary energy generation and improvements in the technology used by these industrial sectors and provinces could drastically reduce the emissions embodied in Chinese exports and thereby global emissions. For example, if the emissions intensity of China's international exports were equal to the intensity of its imports, total emissions embodied in exports as of 2007 would be reduced by $86 \%$, from $1,671 \mathrm{MtCO}_{2}$ to $233 \mathrm{MtCO}_{2}$. In this hypothetical, the avoided emissions are roughly equivalent to the total $\mathrm{CO}_{2}$ emissions of Japan. Even without improving the energy intensity of its economy, decarbonizing China's energy supply to the global average of emissions per US\$ of GDP would reduce the emissions embodied in Chinese exports by $43 \%$ (619 $\left.\mathrm{MtCO}_{2}\right)$. Similarly, Chinese targets to increase the share of energy produced from renewable sources to $20 \%$ of the total by 2020 could reduce exported emissions by $5 \%$.

National economic policy underlines China's carbon-intensive exports. China has for many years prioritized economic growth over environmental management, maintaining $10 \%$ annual economic growth over the past three decades, even as the world experienced a global economic crisis that slowed consumption in the major developed countries that consume most of China's exports. The Chinese government has sustained such a high level of economic growth in part by large capital investments in energy-intensive infrastructure and by favouring industry sectors with high emissions intensity ${ }^{28}$, which has caused China's national carbon intensity to increase by 3\% during 2002-2009 (refs 5,29).

There is now a considerable opportunity to improve the emissions intensity of the Chinese economy by focusing on a small number of provinces and sectors where more energy-efficiency technologies can be installed and by shifting the Chinese energy systems away from coal towards lower-carbon energy sources. Such improvements can be supported by both domestic and international efforts to deploy best-available technologies into critical and still underdeveloped Chinese provinces. Until the vast difference between the emissions intensity of Chinese exports and domestic production in developed countries is reduced, international trade with China will conflict with efforts to reduce global $\mathrm{CO}_{2}$ emissions.

\section{Methods}

Methods and any associated references are available in the online version of the paper.

Received 12 May 2015; accepted 18 August 2015; published online 28 September 2015

\section{References}

1. Kyoto Protocol to the United Nations Framework Convention on Climate Change (UNFCCC, 1997).

2. COP15 Copenhagen Accord (UNFCCC, 2009); http://unfccc.int/files/meetings/cop_15/application/pdf/cop15_cph_auv.pdf

3. Le Quéré, C. et al. The global carbon budget 1959-2011. Earth Syst. Sci. Data 5, 165-185 (2013).
4. Andres, R. J. et al. A synthesis of carbon dioxide emissions from fossil-fuel combustion. Biogeosciences 9, 1845-1871 (2012).

5. Raupach, M. R. et al. Global and regional drivers of accelerating $\mathrm{CO}_{2}$ emissions. Proc. Natl Acad. Sci. USA 104, 10288-10293 (2007).

6. Liu, Z. et al. A low-carbon road map for China. Nature 500, 143-145 (2013).

7. Weber, C. L., Peters, G. P., Guan, D. \& Hubacek, K. The contribution of Chinese exports to climate change. Energy Policy 36, 3572-3577 (2008).

8. Feng, K. et al. Outsourcing $\mathrm{CO}_{2}$ within China. Proc. Natl Acad. Sci. USA 110, 11654-11659 (2013)

9. Le Quéré, C. et al. Global carbon budget 2014. Earth Syst. Sci. Data 7, 47-85 (2015).

10. Jakob, M. \& Marschinski, R. Interpreting trade-related $\mathrm{CO}_{2}$ emission transfers. Nature Clim. Change 3, 19-23 (2013).

11. Minx, J. et al. A "Carbonizing Dragon": China's fast growing $\mathrm{CO}_{2}$ emissions revisited. Environ. Sci. Technol. 45, 9144-9153 (2011).

12. Guan, D., Peters, G. P., Weber, C. L. \& Hubacek, K. Journey to world top emitter: An analysis of the driving forces of China's recent $\mathrm{CO}_{2}$ emissions surge. Geophys. Res. Lett. 36, L04709 (2009).

13. Jiang, X. et al. Revealing the hidden health costs embodied in Chinese exports. Environ. Sci. Technol. 49, 4381-4388 (2015).

14. Liu, Z. China's Carbon Emissions Report 2015 (Harvard Kennedy School, 2015).

15. Liu, Z., Geng, Y., Lindner, S. \& Guan, D. Uncovering China's greenhouse gas emission from regional and sectoral perspectives. Energy 45, 1059-1068 (2012).

16. Feng, K., Siu, Y. L., Guan, D. \& Hubacek, K. Analyzing drivers of regional carbon dioxide emissions for China. J. Ind. Ecol. 16, 600-611 (2012).

17. Lindner, S., Liu, Z., Guan, D., Geng, Y. \& Li, X. $\mathrm{CO}_{2}$ emissions from China's power sector at the provincial level: Consumption versus production perspectives. Renew. Sustain. Energy Rev. 19, 164-172 (2013).

18. Liu, Z. et al. Embodied energy use in China's industrial sectors. Energy Policy 49, 751-758 (2012).

19. Ang, B. W. The LMDI approach to decomposition analysis: A practical guide. Energy Policy 33, 867-871 (2005).

20. Friedlingstein, P. et al. Persistent growth of $\mathrm{CO}_{2}$ emissions and implications for reaching climate targets. Nature Geosci. 7, 709-715 (2014).

21. Liu, Z., Xi, F. \& Guan, D. Climate negotiations: Tie carbon emissions to consumers. Nature 493, 304-305 (2013).

22. Davis, S. J., Peters, G. P. \& Caldeira, K. The supply chain of $\mathrm{CO}_{2}$ emissions. Proc. Natl Acad. Sci. USA 108, 18554-18559 (2011).

23. Davis, S. J. \& Caldeira, K. Consumption-based accounting of $\mathrm{CO}_{2}$ emissions Proc. Natl Acad. Sci. USA 107, 5687-5692 (2010).

24. National Bureau of Statistics China Statistical Yearbook 2013 (China Statistics Press, 2013).

25. Yang, Y. \& Suh, S. Environmental impacts of products in China. Environ. Sci. Technol. 45, 4102-4109 (2011).

26. Introduction to LCA with SimaPro 7 (PRé Consultants, 2008).

27. Yang, D., Liu, J., Yang, J. \& Ding, N. Life-cycle assessment of China's multi-crystalline silicon photovoltaic modules considering international trade. J. Cleaner Prod. 94, 35-45 (2015).

28. Liu, Z. et al. Climate policy: Steps to China's carbon peak. Nature 522, 279-281 (2015)

29. Guan, D. et al. Determinants of stagnating carbon intensity in China. Nature Clim. Change 4, 1017-1023 (2014).

\section{Acknowledgements}

This work was supported by China's National Basic Research Program (2014CB441301) the State Key Laboratory of Urban and Regional Ecology, Chinese Academy of Sciences (SKLURE 2015-2-6), and Natural Science Foundation of China project (41328008). Z. acknowledges the National Natural Science Foundation of China-NSFC 41501605, the China Sustainable Energy Program of Energy Foundation (G-1407-21749), the Giorgio Ruffolo fellowship and the support from Italy's Ministry for Environment, Land and Sea S.J.D. acknowledges support from the Institute of Applied Ecology, Chinese Academy of Sciences Fellowships for Young International Distinguished Scientists. S.L. acknowledges the support of the Dow Sustainability Fellows Program. D.G. acknowledges the Economic and Social Research Council funded project 'Dynamics of Green Growth in European and Chinese Cities' (ES/L016028) and his Philip Leverhulme Prize.

\section{Author contributions}

Z.L., K.F. and S.J.D. designed the research. Z.L., K.F. and S.J.D. conceived the paper. K.F and J.L provided the data Z.L. S.J.D., K.F and K.H performed the analysis. S.J.D drew the figures. All authors contributed to writing the paper.

\section{Additional information}

Supplementary information is available in the online version of the paper. Reprints and permissions information is available online at www.nature.com/reprints. Correspondence and requests for materials should be addressed to S.J.D., K.F. or D.G.

\section{Competing financial interests}

The authors declare no competing financial interests. 


\section{Methods}

Production-based accounting of emissions. Emissions resulting from combustion of fossil fuels or cement production within a territory, or production-based emissions, are the primary basis for national emission inventories ${ }^{30,31}$. For example, the methodology prescribed in IPCC guidelines for greenhouse gas (GHG) emission inventories calculates production-based emissions based on activity data in the region (that is, the amount of energy consumption) and the associated emission factors (that is, GHG emissions per unit energy consumption), the emission factors are based on in situ measurements in which the value is lower than IPCC suggested ${ }^{30}$.

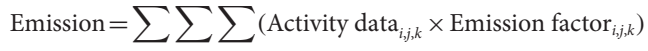

where $i$ is fuel type, $j$ is sector and $k$ is technology type.

Emission factors can be further disaggregated into the net heating value of a certain fuel ' $V$ ', its carbon content ' $F$ ' and the oxidization rate ' $O$ '.

$$
\text { Emission }=\sum \sum \sum\left(\text { Activity data }{ }_{i, j, k} \times V_{i, j, k} \times F_{i, j, k} \times O_{i, j, k}\right)
$$

The detailed calculation process can be found in ref. 30 .

\section{Consumption-based accounting of emissions. An alternative to} production-based accounting of $\mathrm{CO}_{2}$ emissions is to compile inventories according to where related goods and services are ultimately consumed. Such a consumption-based method accounts for inter-regional exchange of energy supply, goods and materials by adding emissions embodied in imports to the production-based total and subtracting emissions embodied in exports.

The emissions embodied in a region's imports and exports can be calculated using environmentally extended input-output analysis (EIO). Environmentally extended multiregional input-output (MRIO) analysis has been widely developed for calculating the embodied carbon emission ${ }^{8,11,23}$, virtual water ${ }^{32,33}$, material use ${ }^{34}$, biodiversity loss ${ }^{35}$ and land use $\mathrm{e}^{36,37}$ associated with international trade.

In the MRIO framework, different regions are connected through inter-regional trade, $Z^{r s}$. The technical coefficient sub-matrix $A^{r s}$ consists of the elements $\left[a_{i j}^{r s}\right]$, derived from $a_{i j}^{r s}=z_{i j}^{r s} / x_{j}^{s}$, where $z_{i j}^{r s}$ is the inter-sector monetary flow from sector in region $r$ to sector $j$ in region $s ; x_{j}^{s}$ is the total output of sector $j$ in region $s$. The final demand matrix $Y$ consists of the elements $\left[y_{i}^{r s}\right]$, where $y_{i}^{r s}$ is the region's final demand for goods of sector $i$ from region $r$. Therefore, MRIO analysis can be represented as

$$
\left[\begin{array}{c}
x^{1} \\
x^{2} \\
x^{3} \\
\vdots \\
x^{n}
\end{array}\right]=\left[\begin{array}{cccc}
A^{11} & A^{12} & \cdots & A^{1 n} \\
A^{21} & A^{22} & \cdots & A^{2 n} \\
A^{31} & A^{31} & \cdots & A^{3 n} \\
\vdots & \vdots & \ddots & \vdots \\
A^{n 1} & A^{n 2} & \cdots & A^{n n}
\end{array}\right]\left[\begin{array}{c}
x^{1} \\
x^{2} \\
x^{3} \\
\vdots \\
x^{n}
\end{array}\right]+\left[\begin{array}{c}
\sum_{s} y^{1 s} \\
\sum_{s} y^{2 s} \\
\sum_{s} y^{3 s} \\
\vdots \\
\sum_{s} y^{n s}
\end{array}\right]
$$

Using familiar matrix notation and dropping the subscripts, equation (1) can be written as: $x=A x+y$ or $x=(I-A)^{-1} y$, where $(I-A)^{-1}$ is the Leontief inverse matrix that captures both direct and indirect inputs required to satisfy one unit of final demand in monetary value; $I$ is the identity matrix. To calculate the consumption-based $\mathrm{CO}_{2}$ emissions, we then extend the MRIO table with sector-specific $\mathrm{CO}_{2}$ emissions: $E=k(I-A)^{-1} y$, where $E$ represents the total $\mathrm{CO}_{2}$ emissions embodied in goods and services used for final demand and $k$ is a vector of $\mathrm{CO}_{2}$ emissions per unit of economic output for all economic sectors in all regions.

Index decomposition analysis of emissions embodied in trade. The index decomposition of trade embodied $\mathrm{CO}_{2}$ emissions is given by

$$
E=\sum_{i} E_{i}=\sum_{i} Q \frac{Q_{i}}{Q} \frac{V_{i}}{Q_{i}} \frac{E_{i}}{V_{i}}=\sum_{i} Q S_{i} I_{i} F_{i}
$$

where $E$ describes $\mathrm{CO}_{2}$ emissions embodied in imports or exports, $Q$ is the GDP value of imports or exports, $S_{i}$ refers to the share of the GDP value for sector $i, I_{i}$ refers to the energy intensity of sector $i$ and $F_{i}$ refers to the emission per unit of energy consumption of of sector $i$ ( $i$ for 46 sectors). Thus, the factors contributing to a net trade in embodied emissions can be expressed based on the logarithmic mean divisia index (LMDI) approach (additive form) $)^{19}$ as:

$$
\Delta E=E^{\text {export }}-E^{\text {import }}=\Delta E_{\text {act }}+\Delta E_{\text {str }}+\Delta E_{\text {int }}+\Delta E_{\text {mix }}
$$

where $\Delta E$ is the difference between the $\mathrm{CO}_{2}$ emissions embodied in exports ( $E^{\text {export }}$ ) and the $\mathrm{CO}_{2}$ emissions embodied in imports $\left(E^{\text {import }}\right) ; \Delta E_{\text {act }}, \Delta E_{\text {str }}, \Delta E_{\text {int }}$ and $\Delta E_{\text {str }}$ refer to economic scale effect, economic structure effect, sector intensity effect and energy mix effect, respectively, where $\Delta E_{\text {act }}, \Delta E_{\text {str }}, \Delta E_{\text {int }}$ and $\Delta E_{\text {str }}$ are expressed as:

$$
\begin{aligned}
\Delta E_{\text {act }} & =\sum_{i} w_{i} \ln \left(\frac{Q_{i}^{t}}{Q_{i}^{0}}\right) \\
\Delta E_{\text {str }} & =\sum_{i} w_{i} \ln \left(\frac{S_{i}^{t}}{S_{i}^{0}}\right) \\
\Delta E_{\text {int }} & =\sum_{i} w_{i} \ln \left(\frac{I_{i}^{t}}{I_{i}^{0}}\right) \\
\Delta E_{\text {mix }} & =\sum_{i} w_{i} \ln \left(\frac{F_{i}^{t}}{F_{i}^{0}}\right) \\
w_{i} & =\frac{E_{i}^{t}-E_{i}^{0}}{\ln E_{i}^{t}-\ln E_{i}^{0}}
\end{aligned}
$$

$Q^{t}, S^{t}, I^{i}$ and $F^{0}$ are the GDP, GDP share, energy intensity and emission coefficient of exports, respectively. $Q^{0}, S^{0}, I^{0}$ and $F^{0}$ are th GDP, GDP share, energy, intensity and emission coefficient of imports, respectively.

Estimates of sectoral level imported and exported $\mathrm{CO}_{2}$ emissions. In a region IO model, a regional economy is considered as its system boundary; thus exports are treated as final products in a region's economy. Let $G_{i}^{r}$ be the total $\mathrm{CO}_{2}$ emissions in economic sector $i$ and region $r$, thus $\Sigma_{i} G_{i}^{r}$ represents the production-based emissions in region $r$. In each region $r$, there is an intermediate consumption, denoted $Z_{i j}^{r}$, which represents the domestic purchases of sector $i$ by sector $j$ in region $r$, and a final consumption, denoted $y_{i}^{r}$, which represents the domestic purchases of sector $i$ by final consumers in region $r$, which includes households, government, capital investments. In the single region IO model, exports, $\mathrm{e}_{i}^{r s}$, from region $r$ to region $s$ are also treated as final consumption. By summing intermediate and final consumption, we can obtain the total output in each region:

$$
x^{r}=Z^{r r}+y^{r r}+\sum_{s} \mathrm{e}^{r s}
$$

By assuming fixed production ratios, we obtain the technical coefficients, $A_{i j}^{r r}$, the ratio of input to output, by dividing $Z_{i j}^{r r}$ by $x_{j}^{r}$ :

$$
A_{i j}^{r r}=Z_{i j}^{r r} / x_{j}^{r}
$$

Thus, equation (2) can be re-written as:

$$
x^{r}=\left(I-A^{r r}\right)^{-1}\left(y^{r r}+\sum_{s} \mathrm{e}^{r s}\right)
$$

where $\left(I-A^{r r}\right)^{-1}$ is Leontief inverse matrix for region $r$.

$\mathrm{CO}_{2}$ emissions are estimated based on the direct emission intensity $k^{r}$ in each sector in region $r$.

$$
k_{i}^{r}=G_{i}^{r} / x_{i}^{r}
$$

Therefore, the total embodied emissions (direct and indirect) in exports from region $r$ to region $s$ can be calculated by:

$$
\operatorname{Exp}^{r}=k^{r}\left(I-A^{r r}\right)^{-1} \hat{\mathrm{e}}^{r s}
$$

where $\operatorname{Exp}^{r}$ is a vector of embodied $\mathrm{CO}_{2}$ emissions in sectoral exports of region $r$ to region $s ; k^{r}$ is a row vector of sectoral emissions intensities in region $r ; \hat{\mathrm{e}}^{r s}$ is a matrix with sectoral export from region $r$ to region $s$ on diagonal.

In turn, the total embodied emissions in imports from region $s$ to region $r$ can be estimated by:

$$
\operatorname{Imp}^{r}=k^{s}\left(I-A^{s s}\right)^{-1} \hat{\mathrm{e}}^{s r}
$$

where $\operatorname{Imp}^{r}$ is a vector of embodied $\mathrm{CO}_{2}$ emissions in sectoral imports of region $s$ to region $r ; k^{s}$ is a row vector of sectoral emissions intensities in region $s ; \mathrm{e}^{s r}$ is a diagonal matrix with sectoral import from region $s$ to region $r$ along the main diagonal.

Emissions and trade data. In this study we estimate emissions from fossil fuel energy combustion and cement production, which together account for about $90 \%$ 
of GHG emissions produced in China. Our calculations include 20 different types of fuel and 46 energy consumption sectors. Further details of data sources and processing methods are available in refs 15,30,38.

Our multiregional input-output (MRIO) relies on data from the Global Trade Analysis Project (GTAP; ref. 39), which includes 129 regions (mostly countries, but some aggregated regions). Although GTAP data covers 57 industry sectors, we aggregate to 30 sectors to match input-output tables of interprovincial trade compiled by Liu et al. at the Chinese Academy of Sciences ${ }^{40}$. In turn, we use Liu et al.'s tables to disaggregate the Chinese region in GTAP into 30 sub-regions (26 provinces and 4 cities). Thus, we have a global MRIO comprised of the latest available economic data that allows us to assess consumption-based $\mathrm{CO}_{2}$ emissions in each Chinese sub-region as well as emissions embodied in trade among these sub-regions and all 129 other GTAP regions around the world. Technical details of how the Chinese IO tables are nested with the GTAP MRIO are available in Feng et al. (2013; ref. 8).

\section{References}

30. Liu, Z. et al. Reduced carbon emission estimates from fossil fuel combustion and cement production in China. Nature 524, 335-338 (2015).

31. IPCC 2006 IPCC Guidelines for National Greenhouse Gas Inventories Vol. 4 (IGES, 2006).
32. Feng, K., Hubacek, K., Pfister, S., Yu, Y. \& Sun, L. Virtual scarce water in China. Environ. Sci. Technol. 48, 7704-7713 (2014).

33. Lenzen, M. et al. International trade of scarce water. Ecol. Econ. 94, 78-85 (2013).

34. Wiedmann, T. O. et al. The material footprint of nations. Proc. Natl Acad. Sci. USA 112, 6271-6276 (2015).

35. Lenzen, M. et al. International trade drives biodiversity threats in developing nations. Nature 486, 110-112 (2012).

36. Yu, Y., Feng, K. \& Hubacek, K. Tele-connecting local consumption to global land use. Glob. Environ. Change 23, 1178-1186 (2013).

37. Weinzettel, J., Hertwich, E. G., Peters, G. P., Steen-Olsen, K. \& Galli, A. Affluence drives the global displacement of land use. Glob. Environ. Change 23, 433-438 (2013).

38. Guan, D., Liu, Z., Geng, Y., Lindner, S. \& Hubacek, K. The gigatonne gap in China's carbon dioxide inventories. Nature Clim. Change 2, 672-675 (2012).

39. Narayanan, B. G., Aguiar, A. \& Walmsley, T. L. Global Trade, Assistance, and Production: The GTAP 8 Data Base (Purdue University, 2012).

40. Liu, W. Theories and Practice of Constructing China's Interregional Input-Output Tables between 30 Provinces in 2007 (Chinese Statistics Press, 2012). 